\title{
Erratum to: Examining the Relationship between Civil Servant Perceptions of Organizational Culture and Job Attitudes: in the Context of the New Public Management Reform in South Korea
}

\author{
Ji Sung Kim ${ }^{1}$ • Seung-Hyun Han ${ }^{2}$
}

Published online: 25 January 2017

(C) Springer Science+Business Media New York 2017

\section{Erratum to: Public Organiz Rev \\ DOI 10.1007/s11115-016-0372-0}

The original version of this article unfortunately contained a mistake. The caption of Fig. 2 is not correct. Figure 2 caption should read as:

Fig. 2 Competing values framework (K. S. Cameron and Quinn (2011))

The original article was corrected.

The online version of the original article can be found at http://dx.doi.org/10.1007/s11115-016-0372-0

Seung-Hyun Han

calebhan@uga.edu

1 Korea University, Seoul, South Korea

2 University of Georgia, Athens, GA 30602, USA 